\title{
Respostas da Tilápia do Nilo (Oreochromis niloticus) à Atratividade e Palatabilidade de Ingredientes Utilizados na Alimentação de Peixes
}

\author{
Elyara Maria Pereira-da-Silva', Luiz Edivaldo Pezzato²
}

\begin{abstract}
RESUMO - Avaliaram-se as respostas da tilápia do Nilo à atratividade e palatabilidade de 14 ingredientes. O método utilizado foi de dupla escolha, comparando-se cada ingrediente peletizado à uma ração controle. Foram empregados quatro aquários (750 litros) contendo, cada um, três alevinos e dois comedouros instalados nos cantos direito e esquerdo, sendo registrados tempo decorrido entre colocação do ingrediente e chegada dos animais aos comedouros, freqüência de visitas aos comedouros, número de grânulos ingeridos e freqüência de ejeções. Os tratamentos foram comparados pela prova não-paramétrica de Kruskal-Wallis e a comparação dos ingredientes para o conjunto de variáveis, por intermédio da “Análise de Agrupamento" e “Análise de Componentes Principais”. Os ingredientes foram assim classificados: a) baixa atrato-palatabilidade = farelos de trigo, soja e algodão, farinha e raspa de mandioca, farinha de girassol e fubá de milho, b) média atrato-palatabilidade = levedura de cana-de-açúcar e glúten de milho e c) alta atrato-palatabilidade = ovo integral liofilizado, farinhas de crisálidas, peixes, carne e camarão. Ingestão de grânulos (manhã e tarde) e freqüência de visitas aos comedouros (tarde) foram consideradas as variáveis mais discriminatórias e freqüência de ejeção de grânulos e tempo gasto para aproximação dos comedouros (manhã e tarde), as menos discriminatórias. As respostas comportamentais dos peixes variaram de acordo com o ingrediente apresentado. A avaliação do grau de atrato-palatabilidade deve ser realizada considerando-se uma combinação de parâmetros.
\end{abstract}

Palavras-chave: atratividade, ingredientes, Oreochromis niloticus, palatabilidade, tilápia do Nilo

\section{Response of Nile Tilapia (Oreochromis niloticus) to the Attraction and Palatability of the Used Ingredients in the Feeding of Fishes}

\begin{abstract}
The response of Nile tilapia to the attraction and palatability of 14 ingredients was evaluated. The two-choice method was used, comparing each pelleted ingredient to a control diet. It was utilized Four aquaria (750 liters) containing in each one three fingerlings and two feed containers at the right and left corner, being recorded the elapsed time between the lay of the ingredient and the arrive of the fingerlings to feed containers, visiting frequency to the feed containers, amount of ingested pellets and ejections frequency. The treatments were compared by non-parametric method of Kruskal-Wallis and the comparison of the ingredients for the variable set using "Grouping Analysis" and "Principal Components Analysis". The numbers of ingested pellets (at morning and at afternoon) and the visiting frequency to feed containers (at afternoon) were considered the most discriminatory variables. The ingredients were classified as it follows: a) low attraction and palatability = wheat meal, soybean meal, cottonseed meal, cassava meal, cassava scrapings, sunflower meal and corn meal), b) medium attraction and palatability = sugar-cane yeast and corn gluten meal and c) high attraction and palatability = integral lyophilized egg, silk worm meal, fish meal, meat meal, shrimp meal. The frequency of ejected pellets and time spent to approach of the feed (at morning and at afternoon) were considered the least discriminatory variables. The behavior response of fishes changes according to the presented ingredient. The attraction and palatability extent must be studied considering combinations of variables.
\end{abstract}

Key Words: attraction, ingredient, Oreochromis niloticus, palatability, Nile tilapia

\section{Introdução}

A alimentação é o processo pelo qual um animal seleciona itens alimentares específicos dentre as fontes presentes no meio, sendo norteado pelos constituintes químicos do alimento e pela sua quimiosensibilidade (ADAMS et al., 1988).

O comportamento alimentar dos peixes é caracterizado por uma seqüência estereotipada de comporta- mentos controlados por várias modalidades sensoriais, dependendo do nicho ecológico do animal, sendo o olfato o primeiro sentido empregado (HARA, 1993). Porém, independentemente dos órgãos sensoriais envolvidos na alimentação, o paladar é considerado o responsável pela seleção final, definindo a ingestão ou a rejeição de um alimento, ou até mesmo a quantidade a ser consumida (ADRON e MACKIE, 1978; RHOADES, 1979; ADAMS e JOHNSEN, 1986; e MEARNS, 1986).

\footnotetext{
1 Depto de Ciências Básicas - FZEA/USP - Pirassununga - SP (CNPq - Processo 831.11189) - CEP: 13.635-900 - CP 23. E.mail: elyara@usp.br 2 FMVZ/UNESP - CAUNESP - Campus de Botucatu/SP, CEP: 18.618-000 - Caixa Postal, 560. E.mail: Ipezzato@fca.unesp.br
} 
Vários autores têm buscado uma classificação para as respostas que os peixes parecem emitir, de modo semelhante, entre as espécies, durante a detecção de um alimento. LINSTED (1971) classificou os elementos químicos presentes nos alimentos em dois grupos: aqueles que exerceriam efeito à distância, podendo desencadear comportamento atrativo ou repelente, e aqueles que requerem contato, tendo ação incitante, repulsora, estimulante ou ainda dispersora. Esta classificação foi complementada por MEARNS et al. (1987), que separaram os alimentos em inibidores, estimulantes, incitantes e excitantes.

O presente trabalho visou avaliar, na tilápia do Nilo (Oreochromis niloticus), a efetividade química de atração de diferentes ingredientes e testar uma nova metodologia de quantificação baseada em variáveis de comportamento alimentar.

\section{Material e Métodos}

O experimento foi conduzido no Laboratório de Nutrição de Organismos Aquáticos da FMVZ, Campus de Botucatu, unidade associada ao Centro de Aqüicultura da UNESP - CAUNESP.

Foram utilizados quatro aquários de amianto com capacidade para 750 litros $(110 \mathrm{~cm} \mathrm{x} 110 \mathrm{~cm} \times$ $65 \mathrm{~cm}$ ), revestidos com material impermeabilizante à base de látex e dotados de sistema de renovação contínua de água proveniente de mina (fluxo de um litro/minuto). Uma barreira confeccionada em madeira e tela metálica foi colocada ao redor da área dos aquários, isolando-os da movimentação rotineira do laboratório e minimizando possíveis efeitos sobre o comportamento dos animais. A luminosidade acompanhou as oscilações naturais do ciclo circadiano e a temperatura da água foi registrada pela manhã $(8 \mathrm{~h})$ e à tarde $(14 \mathrm{~h})$.

Diariamente, todos os aquários foram sifonados para remoção de excretas e/ou restos alimentares não-carreados pelo sistema de renovação de água. As características físicas e químicas da água apresentaram-se semelhantes entre os aquários e dentro da faixa de conforto da espécie em estudo.

Inicialmente, 20 alevinos tilápia do Nilo, nãosexados e com tamanhos próximos entre si (média de $17 \mathrm{~g}$ ), foram transferidos para dois dos aquários (10 animais em cada aquário), onde permaneceram durante 30 dias para aclimatação às condições laboratoriais. Durante essa fase, foram alimentados à vontade com uma ração controle $(28 \%$ PB) pela manhã $(8 \mathrm{~h})$ e à tarde $(16 \mathrm{~h})$.

Após o período de aclimatação, foram seleciona- dos 12 alevinos de pesos e comprimentos próximos entre si $(16,56 \mathrm{~g} \pm 1,97 \mathrm{~g}$ e $75,58 \mathrm{~mm} \pm 2,10 \mathrm{~mm}$, respectivamente), que compuseram quatro grupos de três peixes. Estes foram separadamente transferidos para os aquários descritos, onde permaneceram por mais 30 dias.

Foi avaliado o comportamento alimentar dos peixes frente a 14 ingredientes: farinhas de camarão, peixe, crisálidas, carne, de ovo integral liofilizado, girassol e mandioca, levedura de cana-de-açúcar, glúten de milho, farelos de soja, algodão e de trigo, fubá de milho e raspa de mandioca.

Para obtenção de uma dieta de manutenção dos peixes durante toda fase experimental, que servisse ao mesmo tempo como padrão de comparação mediante confronto com os ingredientes a serem avaliados, foi formulada uma ração (Tabela 1) segundo as normas estabelecidas pelo NATIONAL ACADEMY OF SCIENCE - NAS/NATIONAL RESEARCH COUNCIL - NRC. (1993). A granulação dos ingredientes teste e da ração controle foi realizada adicionando-se amido de milho na razão de 30 e 10\%, respectivamente, sendo obtidos grânulos com diâmetro de 1,8 $\mathrm{mm}$. Após esse processamento, todo material foi identificado, acondicionado em sacos plásticos e armazenado sob refrigeração a $-10^{\circ} \mathrm{C}$.

Além dos fatores relacionados ao sentido predominantemente empregado pelos peixes na detecção e ingestão de um alimento, aqueles referentes ao material teste utilizado (alimento em potencial) foram

Tabela 1 - Composição percentual dos ingredientes e características nutritivas da ração controle/ manutenção

Table 1 - Percentage composition of ingredients and nutritive characteristics of control diet/maintenance

\begin{tabular}{|c|c|c|c|c|}
\hline $\begin{array}{l}\text { Ingrediente } \\
\text { Ingredient }\end{array}$ & $\%$ & $\begin{array}{l}\mathrm{PB} \% \\
C P \%\end{array}$ & $\begin{array}{c}\mathrm{FB} \%^{2} \\
C F \%\end{array}$ & $\mathrm{EE} \%^{3}$ \\
\hline $\begin{array}{l}\text { Premix vit. e min. } \\
\text { Suplement vit and min }\end{array}$ & 1,00 & - & - & - \\
\hline $\begin{array}{l}\text { BHT (antioxidante) } \\
\text { Antioxidant }\end{array}$ & 0,02 & - & - & - \\
\hline $\begin{array}{l}\text { Farinha de peixe } \\
\text { Fish meal }\end{array}$ & 5,00 & 2,88 & 0,0001 & 0,303 \\
\hline $\begin{array}{l}\text { Amido de milho } \\
\text { Corn starch }\end{array}$ & 10,00 & 0,055 & - & 0,018 \\
\hline $\begin{array}{l}\text { Fubá de milho } \\
\text { Corn meal }\end{array}$ & 35,65 & 3033 & 0,634 & 1169 \\
\hline $\begin{array}{l}\text { Farelo de soja } \\
\text { Soybean meal }\end{array}$ & 48,33 & 22,038 & 0,381 & 3122 \\
\hline Total & 100,00 & 28,00 & 1,016 & 4612 \\
\hline
\end{tabular}


considerados. Assim, conforme consideração de WARD (1991), todos os grânulos dos ingredientes utilizados foram apresentados aos animais num mesmo tamanho e forma, porém sua densidade, textura e cor variaram.

A cada um dos aquários foram acoplados dois comedouros confeccionados em tela de nylon, moldados em meio cilindro e presos às bordas direita e esquerda, imersos a $15 \mathrm{~cm}$ de profundidade. Os animais foram alimentados nestes comedouros e condicionados à presença do observador, de modo que anteparos ou espelhos não foram necessários durante as observações.

Diariamente, um dos 14 ingredientes a serem testados foi sorteado, assim como o comedouro a ser preenchido (direito ou esquerdo). Se o ingrediente a ser testado era colocado no comedouro direito, a ração controle permanecia no comedouro esquerdo, e assim sucessivamente. Imediatamente após a oferta simultânea do ingrediente teste (20 grânulos) e da ração controle (20 grânulos) nos comedouros de um aquário, registraram-se durante 20 minutos cronometrados para cada aquário as ocorrências e/ou freqüências dos seguintes eventos: tempo gasto para aproximação do primeiro animal a cada um dos comedouros, freqüência de visitas aos comedouros, número de grânulos ingeridos e frequiência de ejeção de grânulos. Considerou-se grânulo ejetado aquele que, após apreensão, foi devolvido ao substrato, permanecendo até o final das observações.

Decorridos 40 minutos do início da observação, realizou-se a contagem do número de grânulos da ração controle e do ingrediente testado (restantes) nos dois comedouros e no substrato. Esta observação caracterizou a ingestão total de grânulos.

As observações e os registros dos parâmetros avaliados foram repetidos diariamente, pela manhã e à tarde, para cada um dos ingredientes testados e em cada um dos quatro aquários observados, em que o lado sorteado para colocação dos grânulos era idêntico para os dois períodos. Ao final, os aquários foram sifonados para remoção de excretas ou grânulos depositados no substrato. O procedimento experimental descrito foi repetido três vezes para cada ingrediente testado e para cada um dos quatro aquários, de modo a totalizar 12 repetições por ingrediente.

Devido às diferentes variáveis estudadas, a comparação entre os ingredientes foi efetuada utilizando-se a prova não-paramétrica de Kruskal-Wallis (ZAR, 1984). Para visualização comparativa dos in- gredientes no conjunto das variáveis anotadas, foram utilizadas "Análise de Agrupamento" e "Análise de Componentes Principais" (SNEATH e SOKAL, 1973).

\section{Resultados e Discussão}

Os resultados obtidos para as variáveis ingestão total (40 minutos), ejeção de grânulos, tempo decorrido entre a colocação do ingrediente testado e a aproximação do primeiro animal e freqüência de visitas aos comedouros contendo os diferentes ingredientes e a dieta controle possibilitaram a ordenação dos postos médios, obtidos por meio da prova nãoparamétrica de Kruscal-Wallis (ZAR, 1984). Esses postos médios obtidos para as diferentes variáveis foram submetidos à "Análise de Componentes Principais", na qual, entre outras informações, foram obtidos os coeficientes de correlação entre os dois componentes principais (Y1 e Y2) e as variáveis originais. Os coeficientes de correlação indicaram o "peso" e o sentido da contribuição da variável original na formação dos componentes principais que representam combinações lineares destas mesmas variáveis originais. Assim, foi possível a ordenação das variáveis de acordo com seu poder discriminatório e a porcentagem de informação retida pelos dois componentes principais (Y1 e Y2), conforme apresentado na Tabela 2. Observa-se que o componente principal Y1 acumulou $90 \%$ da informação contida no conjunto das variáveis originais.

Existem dois tipos de variáveis originais: aquelas que, assumindo valores maiores, indicam maior atratopalatabilidade (classe 1: freqüência de visitas aos comedouros e número de grânulos ingeridos) e aquelas que indicam maior atrato-palatabilidade, quando assumem menores valores (classe 2: ejeções de grânulos e tempo decorrido entre a colocação do alimento e aproximação dos animais). Em Y1, o "peso" das variáveis da classe 1 foi positivo, o contrário ocorrendo com as variáveis da classe 2. Portanto, devido à maneira como as variáveis contribuem para a formação de Y1, este componente pode ser entendido como um "índice geral discriminatório de qualidade", ou seja, quanto maior o valor de Y1, maiores o potencial de palatabilidade e a atratividade dos ingredientes em estudo.

Observou-se que as variáveis mais discriminatórias (aquelas que apresentaram maiores coeficientes de correlação em valor absoluto, principalmente com Y1) foram ingestão de grânulos no período da manhã e freqüência de visitas aos comedouros no período da 
Tabela 2 - Coeficientes de correlação entre as variáveis analisadas e os dois componentes principais (Y1 e Y2) e classificação das variáveis estudadas quanto ao poder discriminatório

Table 2 - Coefficients of correlation between analysed parameters and the two principal components (Y1 e Y2) and classification of discriminatory power of studied variables

\begin{tabular}{|c|c|c|c|}
\hline $\begin{array}{l}\text { Variáveis } \\
\text { Variable }\end{array}$ & $\mathrm{Y} 1$ & $\mathrm{Y} 2$ & $\begin{array}{l}\text { Classificação } \\
\text { Classification } \\
\end{array}$ \\
\hline Freqüência de visitas aos comedouro (manhã) & 0,943 & 0,250 & 6 \\
\hline $\begin{array}{l}\text { Frequency of visits (at the morning) } \\
\text { Frequiência de visitas aos comedouro (tarde) }\end{array}$ & 0,983 & $-0,014$ & 3 \\
\hline $\begin{array}{l}\text { Frequency of visits (in the afternoon) } \\
\text { Ingestão total de grânulos (manhã) }\end{array}$ & 0,960 & $-0,077$ & 5 \\
\hline Number of swallowed pellets (at the morning) & & & \\
\hline $\begin{array}{l}\text { Ingestão total de grânulos (tarde) } \\
\text { Number of swallowed pellets (in the afternoon) }\end{array}$ & 0,973 & $-0,174$ & 4 \\
\hline $\begin{array}{l}\text { Freqüência de ejeção de grânulos (manhã) } \\
\text { Frequency of ejected pellets (at the morning) }\end{array}$ & $-0,832$ & 0,320 & 7 \\
\hline $\begin{array}{l}\text { Freqüência de ejeção de grânulos (tarde) } \\
\text { Frequency of ejected pellets (in the afternoon) }\end{array}$ & $-0,742$ & 0,428 & 10 \\
\hline $\begin{array}{l}\text { Tempo gasto para aproximação (manhã) } \\
\text { Time spent to approach of the feed (at the morning) }\end{array}$ & $-0,757$ & $-0,557$ & 9 \\
\hline $\begin{array}{l}\text { Tempo gasto para aproximação (tarde) } \\
\text { Time spent to approach of the feed (in the afternoon) }\end{array}$ & $-0,831$ & $-0,208$ & 8 \\
\hline $\begin{array}{l}\text { Ingestão de grânulos (manhã) } \\
\text { Frequency of swallowed pellets (at the morning) }\end{array}$ & 0,985 & 0,098 & 1 \\
\hline $\begin{array}{l}\text { Ingestão de grânulos (tarde) } \\
\text { Frequency of swallowed pellets (in the afternoon) }\end{array}$ & 0,985 & 0,003 & 2 \\
\hline $\begin{array}{l}\% \text { de informação } \\
\% \text { of information }\end{array}$ & 90,60 & 3,47 & - \\
\hline $\begin{array}{l}\text { \% de informação acumulada } \\
\% \text { de accumulated information }\end{array}$ & 90,60 & 94,07 & - \\
\hline
\end{tabular}

tarde e as menos discriminatórias, ejeção de grânulos no período da tarde e tempo gasto para aproximação no período da manhã e tarde.

Em função das considerações anteriores, obtidas na interpretação de Y1 na "Análise de Componente Principais", pode-se constatar a presença de três grupos distintos de ingredientes quanto à atratopalatabilidade: ingredientes de baixa, média e alta atrato-palatabilidade.

\section{Ingredientes de baixa atrato-palatabilidade}

Os valores médios obtidos para as variáveis analisadas são apresentados na Tabela 3. Observa-se que, no período da tarde, a frequiência média de visitas aos comedouros contendo a dieta controle foi superior à dos ingredientes testados, destacando-se maiores diferenças para a farinha de mandioca, enquanto o ingrediente mais atraente foi a farinha de girassol.

Em relação ao número de grânulos ingeridos aos 20 minutos (manhã e tarde), constatou-se, novamente, a superioridade da dieta controle, com ingestão média superior aos demais ingredientes deste grupo. Os ingredientes menos ingeridos, considerados menos palatáveis, foram a farinha de girassol e o farelo de algodão. Já os mais ingeridos, ou mais palatáveis, foram o fubá de milho e a raspa de mandioca. Analisando-se a ingestão total (40 minutos, manhã e tarde), constatou-se novamente que os ingredientes menos ingeridos em relação ao controle foram a farinha de girassol e o farelo de algodão.

Todos os ingredientes, destacando-se a raspa de mandioca, apresentaram freqüência média de ejeção superior ao controle. O ingrediente menos ejetado deste grupo foi a farinha de girassol. O comportamento de ejeção, descrito por MEARNS et al. (1987), pode estar relacionado à presença de substâncias não-agradáveis aos peixes.

Com base nas variáveis mais discriminatórias, ressalta-se que, entre os ingredientes classificados como de baixa atrato-palatabilidade, a farinha de girassol foi a que mais atraiu os peixes, porém foi a menos ingerida comparativamente ao controle. As respostas foram semelhantes para o farelo de algodão, contrariando as afirmações de OIOLLI et al. (1990), quando apresentaram este ingrediente como capaz de proporcionar melhor palatabilidade às rações para peixes.

A alta taxa de aproximação aos comedouros con- 
Rev. bras. zootec.

Tabela 3 - Valores médios obtidos para as variáveis analisadas em ingredientes de baixa atratopalatabilidade. À direita das barras são apresentados os valores obtidos para a ração controle e, entre parênteses, os índices relativos de comparação

Table 3 - Average values obtained for the variables analyzed for ingredients of low attraction and palatability. At right are presented values of control diet and, between parenthesis, the relative indices of comparison

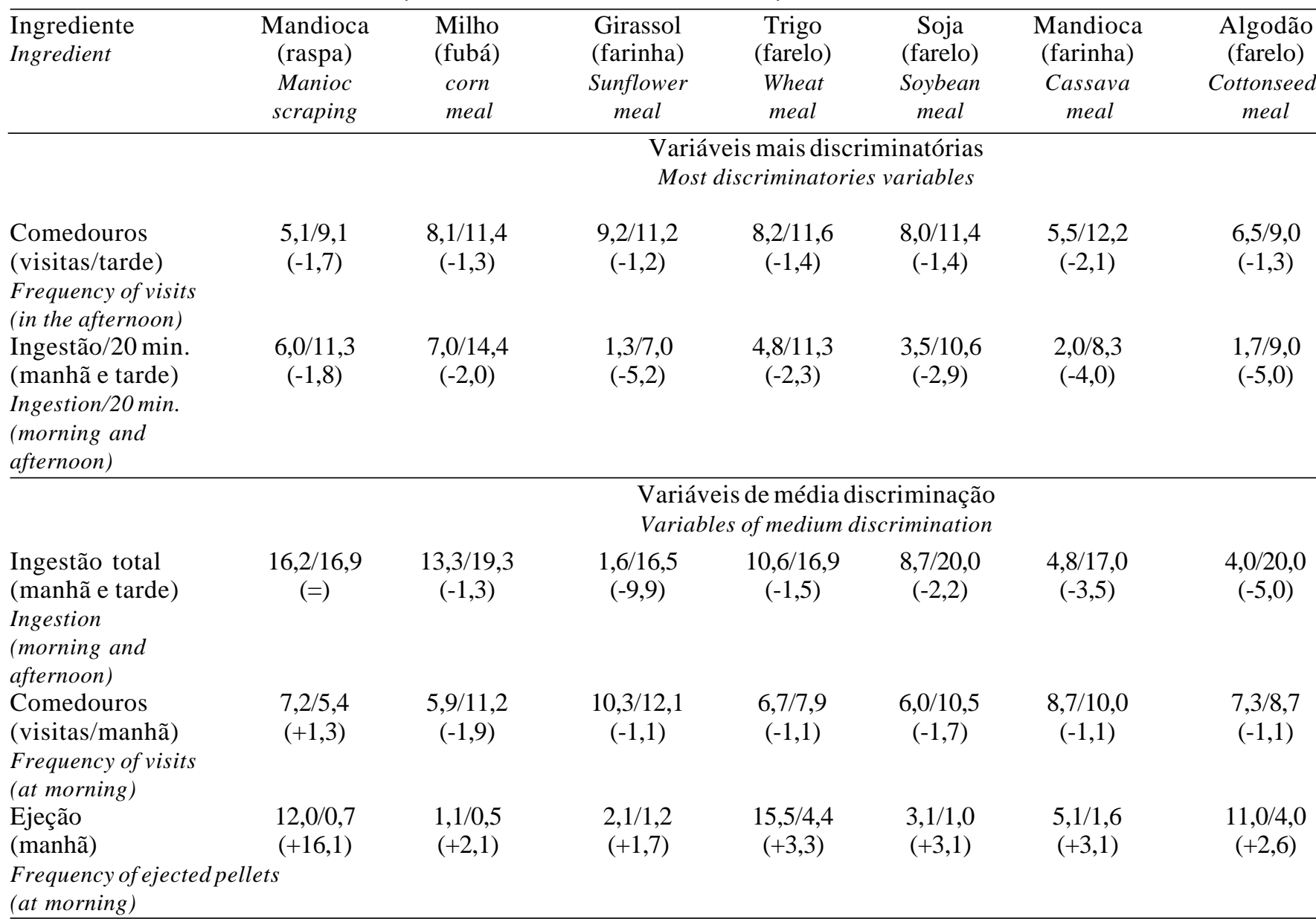

tendo farelo de algodão ou farinha de girassol pode estar relacionada às cores contrastantes de seus grânulos em relação ao substrato, fato anteriormente observado por MASTERSON e GARLING (1986).

A raspa de mandioca, apesar de apresentar baixa atratividade, revelou-se um ingrediente de excepcional poder de indução da ingestão, comparativamente aos demais ingredientes deste grupo, principalmente em relação à farinha de mandioca, que apresentou o menor poder de atração e baixa taxa de ingestão.

Deve-se ressaltar que os ingredientes do presente grupo são comumente empregados na confecção de dietas, como fonte energética (principalmente o fubá de milho e o farelo de trigo, ou ainda a farinha e raspa de mandioca) ou protéica vegetal (principalmente o farelo de algodão, em função de seu baixo preço de mercado e o farelo de soja pelo alto valor nutritivo e disponibilidade no mercado nacional). Entretanto, a atrato-palatabilidade não deve ser definida com base em uma única variável analisada, pois, embora a raspa de mandioca tenha sido classificada como o ingrediente menos atraente, foi a mais ingerida dentro desse grupo. Já a farinha de girassol apresentou alto poder atrativo, mas baixa taxa de ingestão.

Ingredientes de média atrato-palatabilidade

Os valores médios obtidos para as variáveis analisadas são apresentados na Tabela 4. Observa-se que, no período da tarde, a frequiência de visitas aos comedouros contendo levedura de cana-de-açúcar foi superior ao controle. Quando se confrontou a fonte protéica vegetal (glúten de milho) com a protéica microbiana (levedura de cana-de-açúcar), verificou-se que esta foi mais atrativa.

No que se refere ao número de grânulos ingeridos 
Tabela 4 - Valores médios obtidos para as variáveis analisadas em ingredientes de média atratopalatabilidade. À direita das barras são apresentados os valores obtidos para a ração controle e, entre parênteses, os índices relativos de comparação

Table 4 - Average values obtained for the variables analyzed for ingredients of medium attraction and palatability. At right are presented values of control diet and, between parenthesis, the relative indices of comparison

\begin{tabular}{|c|c|c|}
\hline $\begin{array}{l}\text { Ingrediente } \\
\text { Ingredient }\end{array}$ & $\begin{array}{l}\text { Glúten de milho } \\
\text { Corn gluten }\end{array}$ & $\begin{array}{c}\text { Levedura de cana-de-açúcar } \\
\text { Sugarcane yeast }\end{array}$ \\
\hline & \multicolumn{2}{|c|}{$\begin{array}{l}\text { Variáveis mais discriminatórias } \\
\text { Most discriminatories variables }\end{array}$} \\
\hline $\begin{array}{l}\text { Comedouros } \\
\text { (visitas/tarde) }\end{array}$ & $\begin{array}{c}11,5 / 8,3 \\
(+1,3)\end{array}$ & $\begin{array}{l}18,9 / 10,6 \\
(+1,7)\end{array}$ \\
\hline $\begin{array}{l}\text { Frequency of visits } \\
\text { (in the afternoon) }\end{array}$ & & \\
\hline $\begin{array}{l}\text { Ingestão/20 min. } \\
\text { (manhã e tarde) }\end{array}$ & $\begin{array}{c}23,4 / 7,5 \\
(+3,0)\end{array}$ & $\begin{array}{c}12,4 / 9,2 \\
(+1,3)\end{array}$ \\
\hline \multicolumn{3}{|l|}{$\begin{array}{l}\text { Ingestion/20 min. } \\
\text { (morning and afternoon) }\end{array}$} \\
\hline & \multicolumn{2}{|c|}{$\begin{array}{l}\text { Variáveis de média discriminação } \\
\text { variables of medium discrimination }\end{array}$} \\
\hline $\begin{array}{l}\text { Ingestão total } \\
\text { (manhã e tarde) } \\
\text { Ingestion } / 40 \mathrm{~min} \\
\text { (morning and afternoon) }\end{array}$ & $\begin{array}{l}29,1 / 13,4 \\
(+2,1)\end{array}$ & $\begin{array}{l}22,0 / 16,3 \\
(+1,3)\end{array}$ \\
\hline $\begin{array}{l}\text { Comedouros } \\
\text { (visitas/manhã) }\end{array}$ & $\begin{array}{c}12,5 / 7,4 \\
(+1,6)\end{array}$ & $\begin{array}{l}14,5 / 9,0 \\
(+1,6)\end{array}$ \\
\hline $\begin{array}{l}\text { Frequency of visits } \\
\text { (at morning) }\end{array}$ & & \\
\hline $\begin{array}{l}\text { Ejeção } \\
\text { (manhã) }\end{array}$ & $\begin{array}{l}1,6 / 0,7 \\
(+1,7)\end{array}$ & $0,0 / 0,2$ \\
\hline $\begin{array}{l}\text { Frequency of ejected pellets } \\
\text { (at morning) }\end{array}$ & & \\
\hline
\end{tabular}

aos 20 minutos (manhã e tarde), a fonte vegetal resultou em maior ingestão. Isoladamente, em relação à dieta controle, o glúten de milho foi o ingrediente com maior taxa de ingestão.

Analisando-se os ingredientes em relação aos parâmetros de média discriminação, constatou-se que a ingestão total de grânulos do glúten de milho foi superior à dieta controle e levedura de cana-deaçúcar, a qual também superior ao controle.

Quanto à freqüência de visitas aos comedouros no período da manhã, os resultados apresentaram-se semelhantes entre os dois ingredientes, o mesmo não sendo observado no período da tarde. Pode-se inferir, portanto, que a levedura de cana-de-açúcar é mais atrativa para a espécie em estudo. Ao se comparar, ainda, o número médio de visitas entre as duas fontes protéicas, verifica-se que a levedura de cana-deaçúcar também foi mais atrativa.

A freqüência de ejeção de grânulos do glúten de milho no período da manhã foi superior ao controle, não sendo registradas ejeções para a levedura de cana-de-açúcar, fato que corrobora a idéia de que esta seja mais palatável para a espécie, principalmente se for observada a ocorrência de ejeção da dieta controle, especificamente neste tratamento.

A análise global dos resultados permite afirmar que as duas fontes protéicas deste grupo apresentam boa atrato-palatabilidade, cabendo destaque à levedura de cana-de-açúcar, que, isoladamente, pode ser classificada como mais atrativa. Já o glúten de milho, apesar de ter apresentado alta ingestão, também mostrou alta taxa de ejeção.

\section{Ingredientes de alta atrato-palatabilidade}

Com base nos valores obtidos para as variáveis analisadas (Tabela 5), pode-se constatar que as respostas foram semelhantes para todos os ingredientes, que apresentaram atrato-palatabilidade superior à da ração controle.

Em relação à freqüência de visitas aos comedouros no período da tarde, o ovo integral liofilizado foi ingrediente de menor poder de atração. Chama atenção a alta frequiência de visitas observada para as 
Rev. bras. zootec.

Tabela 5 - Valores médios obtidos para as variáveis analisadas em ingredientes de alta atratopalatabilidade. À direita das barras são apresentados os valores obtidos para a ração controle e, entre parênteses, os índices relativos de comparação

Table 5 - Average values obtained for the variables analyzed for ingredients of high attraction and palatability. At right are presented values of control ration and, between parenthesis, the relative indices of comparison

\begin{tabular}{|c|c|c|c|c|c|}
\hline $\begin{array}{l}\text { Ingrediente } \\
\text { Ingredient }\end{array}$ & $\begin{array}{l}\text { Ovo integral } \\
\text { integral } \\
\text { Liofilized egg }\end{array}$ & $\begin{array}{l}\text { Camarão } \\
\text { (farinha) } \\
\text { Shrimp } \\
\text { meal }\end{array}$ & $\begin{array}{c}\text { Carne } \\
\text { (farinha) } \\
\text { Meat } \\
\text { meal }\end{array}$ & $\begin{array}{l}\text { Peixe } \\
\text { (farinha) } \\
\text { Fish } \\
\text { meal }\end{array}$ & $\begin{array}{l}\text { Crisálidas } \\
\text { (farinha) } \\
\text { Silk worm } \\
\text { meal }\end{array}$ \\
\hline & \multicolumn{5}{|c|}{$\begin{array}{l}\text { Variáveis mais discriminatórias } \\
\text { Most discriminatories variables }\end{array}$} \\
\hline $\begin{array}{l}\text { Comedouros } \\
\text { (visitas/tarde) }\end{array}$ & $\begin{array}{l}17,2 / 3,0 \\
(+5,6)\end{array}$ & $\begin{array}{c}19,9 / 6,2 \\
(+3,1)\end{array}$ & $\begin{array}{c}25,4 / 6,9 \\
(+3,6)\end{array}$ & $\begin{array}{c}22,1 / 8,2 \\
(+2,6)\end{array}$ & $\begin{array}{c}19,7 / 7,5 \\
(+2,6)\end{array}$ \\
\hline $\begin{array}{l}\text { Frequency of visits } \\
\text { (in the afternoon) } \\
\text { Ingestão/20 min. } \\
\text { (manhã e tarde) } \\
\text { Ingestion } / 20 \text { min. } \\
\text { (morning and afternoon) }\end{array}$ & $\begin{array}{l}30,0 / 2,9 \\
(+10,3)\end{array}$ & $\begin{array}{c}37.5 / 8.3 \\
(+4.5)\end{array}$ & $\begin{array}{l}36.7 / 5.0 \\
(+7.2)\end{array}$ & $\begin{array}{l}39,9 / 8,0 \\
(+4,9)\end{array}$ & $\begin{array}{c}34,4 / 9,8 \\
(+3,5)\end{array}$ \\
\hline & \multicolumn{5}{|c|}{$\begin{array}{l}\text { Variáveis de média discriminação } \\
\text { Variables of medium discrimination }\end{array}$} \\
\hline $\begin{array}{l}\text { Ingestão total } \\
\text { (manhã e tarde) } \\
\text { Ingestion } \\
\text { (morning and afternoon) }\end{array}$ & $\begin{array}{c}37,0 / 5,9 \\
(+6,2)\end{array}$ & $\begin{array}{l}39,5 / 10,2 \\
(+3,8)\end{array}$ & $\begin{array}{l}40,0 / 14,5 \\
(+2,7)\end{array}$ & $\begin{array}{l}39,9 / 16,2 \\
(+2,4)\end{array}$ & $\begin{array}{l}38,5 / 12,7 \\
\quad(+3,0)\end{array}$ \\
\hline $\begin{array}{l}\text { Comedouros } \\
\text { (visitas/manhã) }\end{array}$ & $\begin{array}{c}17,6 / 3,5 \\
(+4,9)\end{array}$ & $\begin{array}{c}19,8 / 5,6 \\
(+3,5)\end{array}$ & $\begin{array}{c}22,8 / 7,0 \\
(+3,6)\end{array}$ & $\begin{array}{c}18,2 / 8,2 \\
(+2,2)\end{array}$ & $\begin{array}{c}19,4 / 7,6 \\
(+2,5)\end{array}$ \\
\hline $\begin{array}{l}\text { Frequency of visits } \\
\text { (at morning) }\end{array}$ & & & & & \\
\hline $\begin{array}{l}\text { Ejeção (manhã) } \\
\text { Frequency of ejected } \\
\text { pellets (at morning) }\end{array}$ & $0,0 / 0,1$ & $0,0 / 0,4$ & $0,0 / 0,7$ & $0,0 / 0,8$ & $0,0 / 1,2$ \\
\hline
\end{tabular}

farinhas de carne e de camarão. Estes três ingredientes demonstraram eficiência atrativa maior que a da farinha de peixe e semelhante àquela da farinha de crisálidas.

O ingrediente que induziu maior ingestão de grânulos aos 20 minutos de observação (manhã e tarde), comparativamente à dieta controle, foi o ovo integral liofilizado, seguido em ordem decrescente de palatabilidade pelas farinhas de carne, peixe, camarão e de crisálidas.

A alta palatabilidade do ovo integral liofilizado foi novamente revelada, quando se analisou a ingestão total de grânulos aos 40 minutos (manhã e tarde). Porém, neste período, é importante destacar que as respostas induzidas pelos demais ingredientes diferiram daquela observada para o período de 20 minutos, uma vez que a farinha de crisálidas foi ingerida em maior proporção que a farinha de carne. A farinha de camarão foi o segundo ingrediente mais palatável, seguido em ordem decrescente pelas farinhas de crisálidas, carne e peixe.

O ovo integral liofilizado também promoveu a maior freqüência de visitas aos comedouros no período da manhã, resposta que foi observada em menores frequiências para os seguintes ingredientes: farinhas de camarão, carne, crisálidas e peixe (dados apresentados em ordem decrescente).

Uma análise global permite a classificação do ovo integral liofilizado como ingrediente mais atratopalatável. Já os demais ingredientes apresentam atrato-palatabilidade semelhante, apesar de as farinhas de peixe e crisálidas serem classificadas como de menor atrato-palatabilidade, comparativamente às farinhas de camarão e carne.

Os resultados observados podem ser atribuídos à presença de aminoácidos responsáveis pelo desencadeamento do comportamento alimentar nos peixes. De fato, WARD (1991) atribuiu a capacidade diferencial de atratividade de um alimento a diferenças qualitativas e quantitativas de seus 
aminoácidos e SHPARKOVSKYI et al. (1983) e JOHNSEN e ADAMS (1986) citam aminoácidos na água como elementos desencadeadores do comportamento alimentar em peixes.

\section{Conclusões}

As respostas comportamentais apresentam-se diferenciadas, em função do grau de atratopalatabilidade dos ingredientes alimentares.

Os farelos de trigo, algodão e soja, a farinha e raspa de mandioca, a farinha de girassol e o fubá de milho são de baixa atrato-palatabilidade, sendo a farinha de girassol o ingrediente mais atrativo e a raspa de mandioca o mais palatável.

A levedura de cana-de-açúcar e o glúten de milho são ingredientes de média atrato-palatabilidade, sendo o glúten de milho o mais atrato-palatável.

O ovo integral liofilizado e as farinhas de crisálidas, peixe, carne e camarão são ingredientes de alta atratopalatabilidade, destacando-se o ovo como o mais atratopalatável dentre esses ingredientes.

O comportamento alimentar dos peixes deve ser avaliado considerando-se uma combinação de fatores, sendo o número de grânulos ingeridos e a frequiência de visitas aos comedouros os mais significativos.

Sugere-se que ingredientes classificados como de alta atrato-palatabilidade sejam adicionados a dietas especiais para peixes, visando-se ao aumento da ingestão alimentar em períodos pré-invernais, situações de estresse ou estados patológicos.

\section{Referências Bibliográficas}

ADAMS, M.A., JOHNSEN, P.B. 1986. A solid matrix bioassay for determining feeding stimulants. Prog. Fish. Cult., 48(1):147-149.

ADAMS, M.A., JOHNSEN, P.B., HONG-QI, Z. 1988. Chemical enhencement of feeding for the herbivorous fish Tilapia zillii. Aquaculture, 72(1):95-107.

ADRON, J.W., MACKIE, A.M. 1978. Studies on the chemical nature of feeding stimulants for rainbow trout, Salmo gairdneri Richardson. J. Fish Biol., 12(1):202-310.
HARA, T.J. 1993. Role of olfaction in fish behaviour. In: PITCHER, T.J. (Ed.) Behaviour of teleost fishes. London: Chapman \& Hall. 2.ed. p.171-199.

JOHSEN, P.B., ADAMS, M.A. 1986. Chemical feeding stimulants for the herbivorous fish, Tilapia zillii. Comp. Biochem. Physiol., 83(1):109-112.

LINSTED, K.J. 1971. Chemical control of feeding behaviour. Comp. Biochem. Physiol., 39A(1):553-81.

MASTERSON, M.F., GARLING, D.L. 1986. Effect of feed colour on feed acceptance and growth of walleye fingerlings. Prog. Fish. Cult., 48(1):306-309.

MEARNS, K.J. 1986. Sensitivity of brown trout (Salmo trutta L.) and Atlantic salmon (Salmo salar L.) fry to amino acids at the start of exogeneous feeding. Aquaculture, 55(1):191-200.

MEARNS, K.J., ELLINGSEN, O.F., DOVING, K.B. 1987. Feeding behaviour in adult rainbow trout and Atlantic salmon Parr, elicited by chemical fractions and mixtures of compounds identified in shrimp extract. Aquaculture, 64(1):47-63.

NATIONAL ACADEMY OF SCIENCE - NAS/NATIONAL RESEARCH COUNCIL - NRC. 1993. Nutrient requeriment of warm water fishes and shellfishes. 1.ed. Washington D.C. 102p.

OIOLLI, K.V., SILVEIRA, A.C., LUVIZOTTO, M.C. 1990. Desempenho produtivo e alterações anatomopatológicas, resultantes da utilização do farelo de algodão na alimentação inicial da tilápia-do-Nilo (Oreochromis niloticus). Bol. Red. Acuicultura, 3(2):25-32.

HOADES, D.F. 1979. Evolution of plant chemical defense against herbivores. In: ROSENTHAL, G.A., JANZEN, D.H. (Eds.) Herbivores: theirinteraction with secondary plant metabolites. New York: Academic Press. 2.ed, p.3-54.

SHPARKOVSKYI, I.A., PAVLOV, J.D., CHINARINA, A.D. 1983. Behaviour of young hatchery reared Atlantic salmon Salmo salar (Salmonidae) influenced by aminoacids. $J$. Ichthyol, 4(1):140-148.

SNEATH, P.H.A., SOKAL, R.R. 1973. Numerical taxonomy. 1.ed. San Francisco: W.H. Freeman. 234p.

WARD, N.E. 1991. Amino acids: aquafeed "attractants". Feed International, 9:34-40.

ZAR, J.H. 1984. Bioestatistical analysis. 2.ed. Englewood: Englewood Cliffs Prentice-Hall. 718p.

Recebido em: 02/02/99

Aceito em: 31/03/00 